\title{
Validated Gradient Stability Indicating UPLC Method for the Determination of Related Substances of Posaconazole in Bulk Drug
}

\author{
Vadlamanu Durga Prasad1 ${ }^{*}$, Vanga Ranga Reddy², Pasula Aparna ${ }^{3}$ \\ ${ }^{1}$ Department of Analytical Development, AET Laboratories, Hyderabad, India \\ ${ }^{2}$ Department of Analytical Development, IPDO, Hyderabad, India \\ ${ }^{3}$ Department of Chemistry, JNTU, Hyderabad, India \\ Email: *vdprasad1986@gmail.com
}

Received 27 September 2015; accepted 27 November 2015; published 30 November 2015

Copyright (C) 2015 by authors and Scientific Research Publishing Inc.

This work is licensed under the Creative Commons Attribution International License (CC BY). http://creativecommons.org/licenses/by/4.0/

(c) (†) Open Access

\section{Abstract}

A stability-indicating UPLC method has been developed and validated for the determination of related substances of Posaconazole with its four related substances (Hydroxytriazole, Tosylated compound, Deshydroxy posaconazole and Benzylated posaconazole) in the drug substance. Forthwith simple UPLC chromatographic separations were achieved on a Waters Acquity BEH shield $\mathrm{C}_{18}$ (100 mm length, $2.1 \mathrm{~mm}$ internal diameter and $1.7 \mu \mathrm{m}$ particle size) with a mobile phase containing $0.1 \%$ Orthophosphoric acid (i.e. $1 \mathrm{~mL}$ in $1000 \mathrm{~mL}$ water) in gradient combination with acetonitrile (ACN) at a flow rate of $0.5 \mathrm{~mL} / \mathrm{min}$ and the eluent were monitored at $210 \mathrm{~nm}$. As a result, the resolution of Posaconazole from any of impurities was found to be greater than 2.0. The test solution and spiked solutions were found to be stable in the diluent for $48 \mathrm{~h}$. For the purpose method to be stability indicating, forced degradation studies were conducted and the method resolved the drug from its known impurities, stated above, and from additional impurities generated when POS subjected to forced degradation; the mass balance was found close to $100 \%$. Regression analyses indicate correlation coefficient value greater than 0.999 for Posaconazole and its known impurities. The LOD for Posaconazole and the known impurities was at a level below $0.05 \%$. The method has shown good, consistent recoveries for known impurities $(89 \%-106 \%)$. To summarise, the method was found to be accurate, precise, linear, specific, sensitive, rugged, robust, and stability-indicating.

\section{Keywords}

Posaconazole, Hydroxytriazole, Tosylated, Deshydroxy Posaconazole, Benzylated Posaconazole, Stability-Indicating, ICH Guidelines, UPLC

\footnotetext{
${ }^{*}$ Corresponding author.
}

How to cite this paper: Prasad, V.D., Reddy, V.R. and Aparna, P. (2015) Validated Gradient Stability Indicating UPLC Method for the Determination of Related Substances of Posaconazole in Bulk Drug. American Journal of Analytical Chemistry, 6, 965-976. http://dx.doi.org/10.4236/ajac.2015.612092 


\section{Introduction}

Posaconazole (POS) 4-[4-[4-[4-[[(3R,5R)-5-(2,4-difluorophenyl)tetrahydro-5-(1H-1,2,4-triazol-1-ylmethyl)-3furanyl]methoxy]phenyl]-1-piperazinyl]phenyl]-2-[(1S,2S)-1-ethyl-2-hydroxypropyl]-2,4-dihydro-3H-1,2,4triazol-3-one (Figure 1) [1]. Available under the brand names Noxafil oral suspension (40 $\mathrm{mg}$ per $\mathrm{mL}$ ) and Noxafil 100 mg Gastro-resistant tablets [2] from the MSD (Merck Sharp \& Dohme Ltd, Hertford Road, Hoddesdon Hertfordshire EN11 9BU United Kingdom)-Used for the Prevention of invasive Aspergillus and Candida infections in severely immune compromised adults and adolescents $\geq 13$ years of age, including hematopoietic stem cell transplant (HSCT) recipients with graft-versus-host-disease (GVHD) and patients with hematologic malignancies and prolonged chemotherapy-associated neutropenia [3]-[5]. The administration of drug is done orally during or immediately following a full meal or liquid nutritional supplement. Alternatively may be administered with an acidic beverage. Has been administered via nasogastric (NG) tube [6] closely monitor such patients for breakthrough fungal infections since systemic exposure may be lower and may be associated with an increased risk of treatment failure.

Regulatory requirements for the identification, qualification, and control of impurities in drug substances and their formulated products are now being explicitly defined, particularly through the International Conference on Harmonization (ICH). It is also recommended by ICH that all routine impurities at or above the $0.1 \%$ level, should be identified through appropriate analytical methods [7]-[9]. In the synthesis of Posaconazole, the process related impurities are identified by MSN laboratories, they are Hydroxytriazole, Tosylated compound, Deshydroxy posaconazole and Benzylated posaconazole (Figure 1) [10]. For the purpose of determining the impurities of Posaconazole to ensure the quality, efficacy and safety of the active ingredient and final pharmaceutical formulation. The four processes related impurities, a method for analyzing POS in the presence of these impurities, and the degradants obtained during forced degradation studies was required to be developed for the method is to be stability indicating.

\section{Experimental}

\subsection{Reagents and Chemicals}

Qualified standards of POS, Hydroxytriazole, Tosylated compound, Deshydroxy posaconazole, Benzylated posaconazole were obtained from MSN laboratories Pvt. Ltd. Posaconazole drug substance is obtained from MSN laboratories. Analytical/HPLC grade chemicals and solvents used were obtained from Merck Chemicals Limited.

\subsection{Chromatography Instruments and Conditions}

The chromatograph consisted of Waters UPLC system with Acquity Binary solvent manager, Acquity sample manager, Acquity PDA (Photo diode array detector). The data were evaluated by Empower3 Software.

Posaconazole has pKa value of 3.6 [11] and is freely soluble in selected analytical solvents like Acetonitrile (ACN) and methanol (MeOH). The chromatographic conditions were optimized by different means (using different columns, different buffers and different organic phases). Early chromatography work was performed with different Acquity UPLC-BEH Shield $\mathrm{C}_{18}$ and Acquity UPLC-HSS $\mathrm{C}_{18}$ columns as stationary phase and various combinations of buffered ( $\mathrm{pH} 2-7$ ) organic phases (ACN). The flow rate of the mobile phase was varied within $0.45-0.55 \mathrm{~mL} / \mathrm{min}$. Wavelength for monitoring the eluent was selected by scanning standard solution of the drug within 200 - $400 \mathrm{~nm}$ using a PDA detector.

All noted, measurements were performed with an injection volume of $1 \mu \mathrm{L}$ and UV detection at $210 \mathrm{~nm}$ of samples dissolved in a diluent [water: Acetonitrile (40:60) v/v]; Mobile phase-A [0.1\% Orthophosphoric acid (OPA) $\mathrm{pH}$ adjusted to 2.1; Mobile phase-B [ACN]. The optimized gradient program is a Time (min)/\%Mobile Phase-B ( $0 \mathrm{~min} / 30 \%, 3 \mathrm{~min} / 30 \%, 10 \mathrm{~min} / 70 \%, 15 \mathrm{~min} / 70 \%, 16 \mathrm{~min} / 30 \%$ and $18 \mathrm{~min} / 30 \%$ ).

\subsection{Preparation of Solutions}

\subsubsection{Preparation of Resolution Solution}

Like wise with official procedures [8], impurity stock solutions of Hydroxytriazole (44 $\mu \mathrm{g} / \mathrm{mL})$, Tosylated compound $(93 \mu \mathrm{g} / \mathrm{mL})$, Deshydroxy posaconazole $(57 \mu \mathrm{g} / \mathrm{mL})$ and Benzylated posaconazole $(77 \mu \mathrm{g} / \mathrm{mL})$ were individually prepared by dissolving their appropriate amounts in the diluent. 

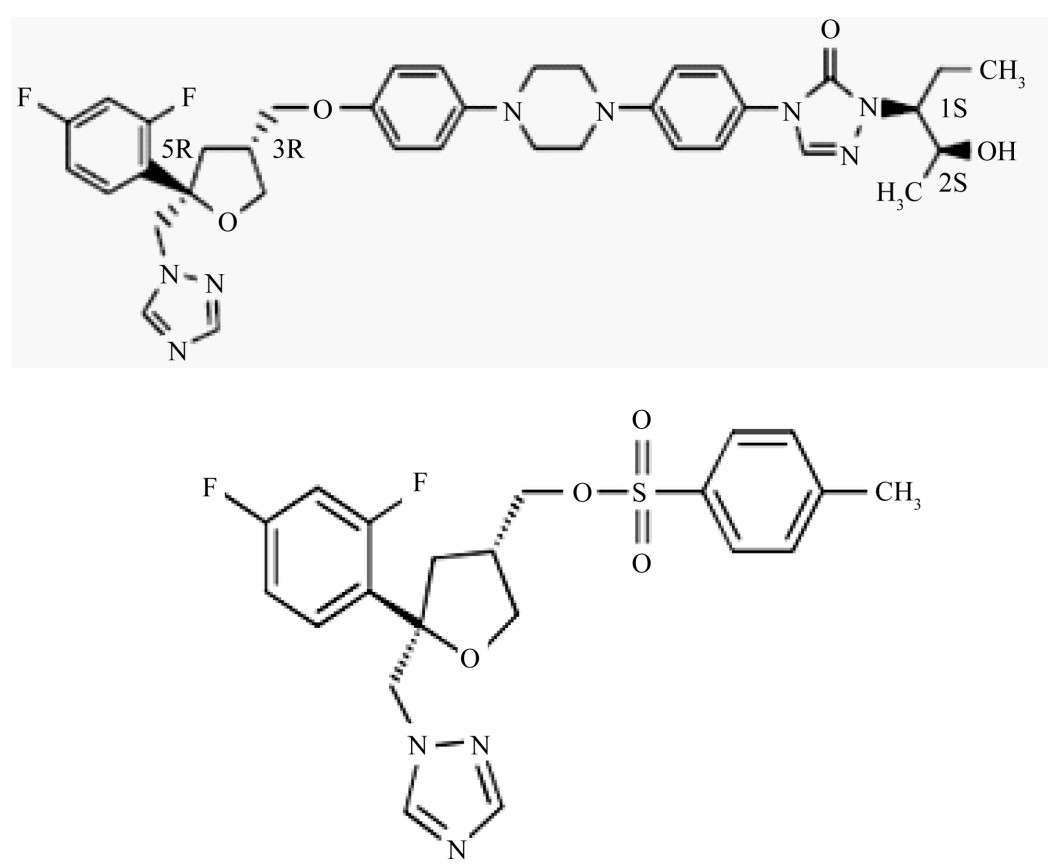

Tosylated compound: (5R,cis-Toluene-4-sulfonic acid-5-(2,4-diflourophenyl)-

5-(1H-1,2,4-triazol-1-yl)methyltetrahydrofuran-3-yl methyl ester

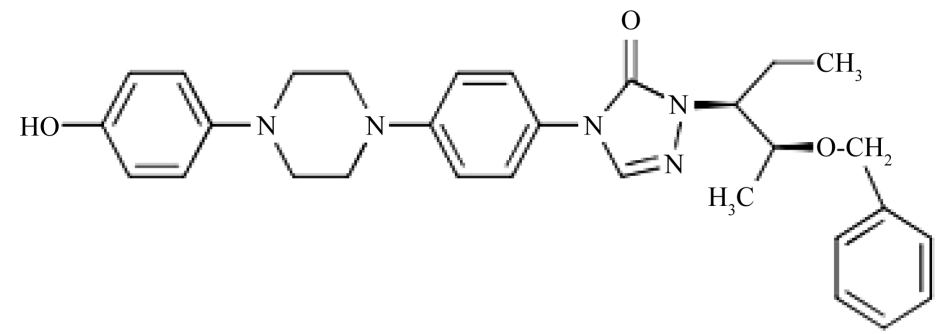

Hydroxytriazole:1-((2S,3R)-2-(benzyloxy)pentan-3-yl)-4-(4-(4-(4-hydroxyphenyl)piperazin-1-yl)phenyl) -1H-1,2,4-triazol-5(4H)-one<smiles>CCC(CC)n1ncn(-c2ccc(N3CCN(c4ccc(OC[C@@H]5CO[C@@](Cn6cncn6)(c6ccc(F)cc6F)C5)cc4)CC3)cc2)c1=O</smiles>

Deshydroxy posaconazole:4-(4-(4-(4-(((3R,5R)-5((1H-2,2,4-triazol-1-yl)methyl)-5-(2,4difluorophenyl) tetrahydrofuran-3-yl)methoxy)phenyl)-piperazin-1-yl)phenyl)-1(pentan-3yl)-1H-1,2,4-triazol-5(4H)-one<smiles>CCC([C@H](C)Oc1ccccc1)n1ncn(-c2ccc(N3CCN(c4ccc(OC[C@@H]5CO[C@@](Cn6cncn6)(c6ccc(F)cc6F)C5)cc4)CC3)cc2)c1=O</smiles>

Benzylated posaconazole: 4-(4-(4-(4-(((3R,5R)-5((1H-1,2,4-triazol-1-yl)methyl)5-(2,4-diflurophenyl)tetrahydrofuran-3-yl) methoxu)phenyl)piperazin-1yl)phenyl)-1-((2S,3S)-2-(benzyloxy)pentan-3-yl)-1H-1,2,4-triazol-5(4H)-one

Figure 1. Chemical structures and IUPAC names for Posaconazole and related compounds. 
POS (200 mg) was transferred in to $50 \mathrm{~mL}$ volumetric flask added $20 \mathrm{~mL}$ of diluent and sonicated to dissolve added $3.2 \mathrm{~mL}$ of Tosylated stock, $7 \mathrm{~mL}$ of Hydroxy triazole, $6 \mathrm{~mL}$ of Deshydroxy posaconazole and $4 \mathrm{~mL}$ of Benzylated posaconazole each of above impurity solutions was added and sonicated for 5 min. The volume of thus obtained clear solution was made up to with the diluent. Diluted $5 \mathrm{~mL}$ to $10 \mathrm{~mL}$ with diluent to give the resolution solution containing $2000 \mu \mathrm{g} / \mathrm{mL}$ POS, about $3 \mu \mathrm{g} / \mathrm{mL}$ each of Hydroxy triazole, Tosylated compound, Benzylated posaconazole and about $3.4 \mu \mathrm{g} / \mathrm{mL}$ of Deshydroxy Posaconazole.

Diluted standard of POS $(2 \mu \mathrm{g} / \mathrm{mL})$ was prepared by dissolving appropriate amount of the drug in the diluent.

\subsubsection{Preparation of Laboratory Mixture Solutions}

Appropriate amounts of active pharmaceutical ingredient (POS) and impurity stock solutions of Hydroxytriazole (44 $\mu \mathrm{g} / \mathrm{mL})$, Tosylated compound $(93 \mu \mathrm{g} / \mathrm{mL})$, Deshydroxy posaconazole $(57 \mu \mathrm{g} / \mathrm{mL})$ and Benzylated posaconazole $(77 \mu \mathrm{g} / \mathrm{mL})$ were individually prepared by dissolving their appropriate amounts in the diluent.

\subsubsection{Preparation of Sample Solution}

An amount of drug (POS, $100 \mathrm{mg}$ ), active pharmaceutical ingredient (POS) was transferred to a $50 \mathrm{~mL}$ volumetric flask. Diluent $(30 \mathrm{~mL})$ added to it and sonicated for $5 \mathrm{~min}$ with intermittent shaking and diluted to volume with the diluent.

\subsection{System Suitability}

System suitability parameters are to be evaluated to show analytical conditions are suitable to get reliable results. Parameters such as peak asymmetry factor, tailing factor, resolution between tosyalted compound and deshydroxy posaconazole, resolution between Hydroxytriazole and Posaconazole, and \% RSD of the area obtained from standard solution of POS was evaluated.

\subsection{Analytical Method Validation}

\subsubsection{Specificity}

Specificity is the ability to assess unequivocally the analyte in the presence of components which may be expected to be present. Typically these might include impurities, degradants, matrix, etc. [12]. Specificity can be assessed in two parts.

In one part of specificity, separation and resolutions were observed between POS and its four known impurities namely), Hydroxytriazole, Tosyalted compound, Deshydroxy posaconazole and Benzylated posaconazole. In another part of specificity drug was exposed to different stress conditions [13] like hydrolysis conditions at all the $\mathrm{pH}$ ranges (Acid, Alkaline and Neutral water) and oxidative conditions at a concentration of $2 \mathrm{mg} / \mathrm{mL}$. The drug samples were also subjected to thermal and photolytic degradation. The stressed samples were analyzed on UPLC with Photo diode array detector and calculations were done using standard solution. The Peak purity evaluation and mass balance studies were done for each type of stress study.

\subsubsection{Linearity}

The linearity of the method was performed according to ICH Quality guidelines. Suitable aliquots of POS stock solution were spiked with appropriate volumes of stock solutions of known impurities (related substances) and diluted with the diluent to get solutions containing target concentrations. Linearity of POS and its related substances was determined over a range of obtained limit of quantification (shown in Table 1) to $150 \%$ of specification limit (range was inclusive of concentrations at LOQ, 50\%, 100\% and 180\%).

Calibration curve was obtained by plotting the peak areas of POS and its known impurities versus its corresponding concentration. Values of the coefficient of correlation, regression and slope of the calibration curve were calculated. The relative response factors (CF) of all RS were calculated and concentrations were adjusted accordingly.

\subsubsection{Precision}

Six solutions containing POS $(2000 \mu \mathrm{g} / \mathrm{mL})$ were spiked with Known impurity solutions $2.5 \mu \mathrm{g} / \mathrm{mL}$. Chromatography was performed by UPLC and value of \% RSD was calculated for Percentage of known impurities by considering the peak area for POS standard and each known impurity. In a similar way the intermediate 
Table 1. Linearity parameters of the calibration curves for POS and its known impurities.

\begin{tabular}{cccccc}
\hline Compound & $\begin{array}{c}\text { Linearity range } \\
(\boldsymbol{\mu g} / \mathbf{m L})\end{array}$ & Correlation $\boldsymbol{R}$ & Regression $\mathbf{R}^{2}$ & Slope & CF \\
\hline POS & 1.04 to 4.44 & 0.9998 & 0.9997 & 95060.6 & 1.00 \\
Hydroxytriazole & 1.09 to 4.54 & 0.9999 & 0.9999 & 134497.6 & 0.71 \\
Tosylated compound & 1.06 to 4.44 & 0.9999 & 0.9999 & 61495.9 & 1.55 \\
Deshydroxy posaconazole & 1.03 to 4.29 & 0.9999 & 0.9997 & 100339.3 & 0.95 \\
Benzylated posaconazole & 1.08 to 4.48 & 0.9990 & 0.9981 & 120586.9 & 0.79 \\
\hline
\end{tabular}

precision of the method was also evaluated on different days by another analyst in the same laboratory.

\subsubsection{Limit of Detection (LOD) and Limit of Quantification (LOQ)}

The LOD and LOQ for POS and all known impurities were estimated by signal-to-noise ratio of 3:1 and 10:1, respectively, injecting a series of diluted solutions with known concentrations.

\subsubsection{Accuracy}

Accuracy studies were done in triplicate at concentration levels of LOQ, 100 and $180 \%$ of POS $(2000 \mu \mathrm{g} / \mathrm{mL})$ to evaluate the recovery and accuracy of the proposed method. The stock solutions of Known impurities from laboratory mix solution were taken for this study.

\subsubsection{Stability of Analytical Solutions}

The stability of accuracy and precision solutions were evaluated at regular intervals for $24 \mathrm{~h}$. The difference in percentage of impurities obtained with initial results was calculated.

\subsubsection{Robustness}

The method was subjected with little variations by changing the mobile phase flow rate $( \pm 0.05 \mathrm{~mL} / \mathrm{min})$, and increasing the temperature from normal $\left( \pm 5^{\circ} \mathrm{C}\right)$. Chromatograms of POS standards and system suitability solutions were evaluated by applying system suitability parameters with the robustness changes made.

\section{Results and Discussion}

\subsection{Development of the Stability-Indicating UPLC Method}

Published HPLC method [10] to analyze POS and its four known impurities was not found to be rugged method. Following these methods, the column cooler temperature of $18^{\circ} \mathrm{C}$ is required and for waters HPLC systems the temperature is not possible to achieve and the resolutions between POS, Hydroxytriazole, and Tosylated compound are very less. The methods were not able to give sufficient resolution between known impurities with POS. The run time is also more. In order to get better resolution for peaks with less run time a stability indicating UPLC method is developed for related substances of POS.

Another official method [14] does not include all the specified known impurities present in this study. And also it required longer saturation time of the HPLC-system, probably due to the use of $150 \mathrm{~mm}$ length column and more column volumes are required for the saturations and it requires dual wavelength for detection of impurities.

From the observations of the official methods, it was thought that an UPLC method developed to have better separations for different polarity ranges of molecules with simple buffers like $0.1 \%$ Orthophosphoric acid in water as Mobile phase-A and Acetonitrile as Mobile phase-B. The advantages with UPLC methods are shorter run times and quick development trails are possible without affecting the separation in comparison to HPLC. During the initial development of chromatography, screening studies were done on HPLC with different Mobile phase $\mathrm{pH}$ (2 to 7), from the observations of the $\mathrm{pH}$ screening study, in effect that lower $\mathrm{pH}$ of the mobile phase is suitable for the proper separations of POS and related known impurities. The advantage with lower $\mathrm{pH}$ was also getting of good peak shapes.

Based on the development study a simple buffer ( $0.1 \%$ Orthophosphoric acid) is selected as mobile phase-A 
and Acetonitrile as counterpart viz. mobile phase-B. The chromatographic elution is performed in Acquity BEH shield $\mathrm{C}_{18}$ columns. The finalized method has a gradient composition of optimum separations of POS RS were obtained on Acquity BEH Shield $\mathrm{C}_{18}$ (Waters Acquity BEH Shield $\mathrm{C}_{18} 100 \mathrm{~mm}$ length, $2.1 \mathrm{~mm}$ internal diameter and $1.7 \mu$ particle size), injection volume $2 \mu \mathrm{L}$, column temperature $30^{\circ} \mathrm{C}$ and eluent is monitored at $210 \mathrm{~nm}$.

\subsection{System Suitability}

System suitability is the primary requirement of the any methodology, to ensure that the working conditions are fit for its intended use. The chromatography was performed with Acquity BEH shield C18 (100 mm length, 2.1 $\mathrm{mm} \mathrm{I.D} \mathrm{and} 1.7 \mu \mathrm{m}$ particle size) with gradient mentioned in chromatography conditions. A representative is shown in Figure 2, which shows Resolution between any two peaks is more than 2.0 and tailing factor for POS is less than 2.0. The response ratio obtained for two $0.1 \%$ POS standard injections is between 0.95 to 1.05 .

\subsection{Specificity}

The UPLC chromatograms recorded separately for Blank, POS alone and with its related impurities and displayed in Figures 2-4 respectively. The resolution obtained between POS main peak with Hydroxy triazole, Deshydroxy, Tosylated and Benzylated posaconazole is more than 2.0. The tailing factor for POS peak is 0.91. Thus the UPLC method presented in this study is specific for POS and its related four impurities. To have stability indicating nature of the method, forced degradation studies of POS evaluated and the following degradation behavior is shown, the results were tabulated in Table 2 .

\subsubsection{Degradation in Acidic Conditions}

POS was found stable in acidic conditions, when hydrolyzed with $0.1 \mathrm{M} \mathrm{HCl}$ for $3 \mathrm{~h}$ at $60^{\circ} \mathrm{C}$. Acidic degradation

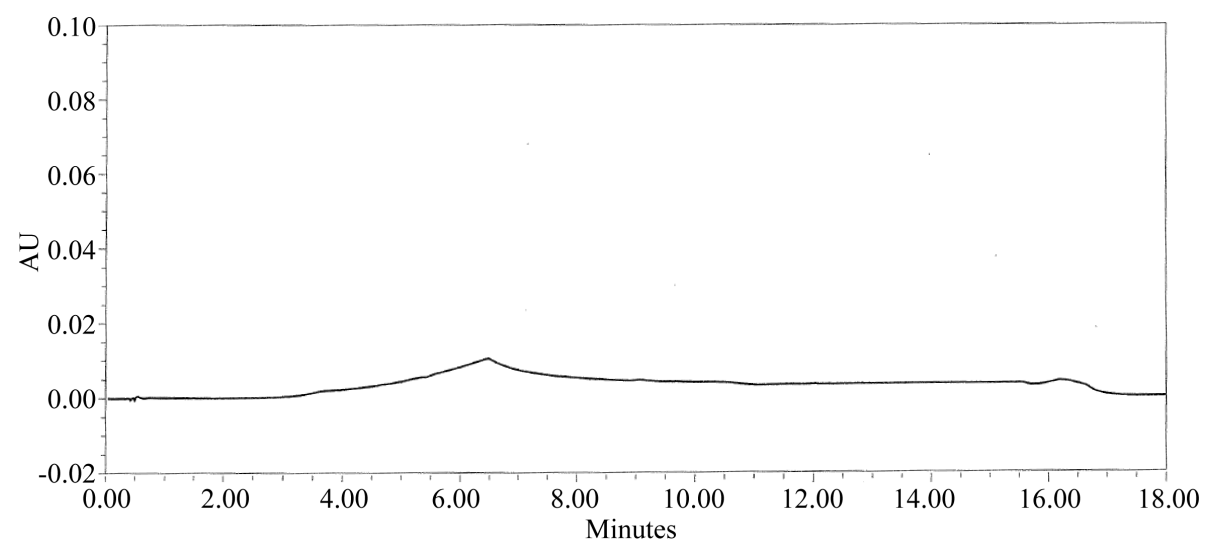

Figure 2. Chromatogram of diluent solution.

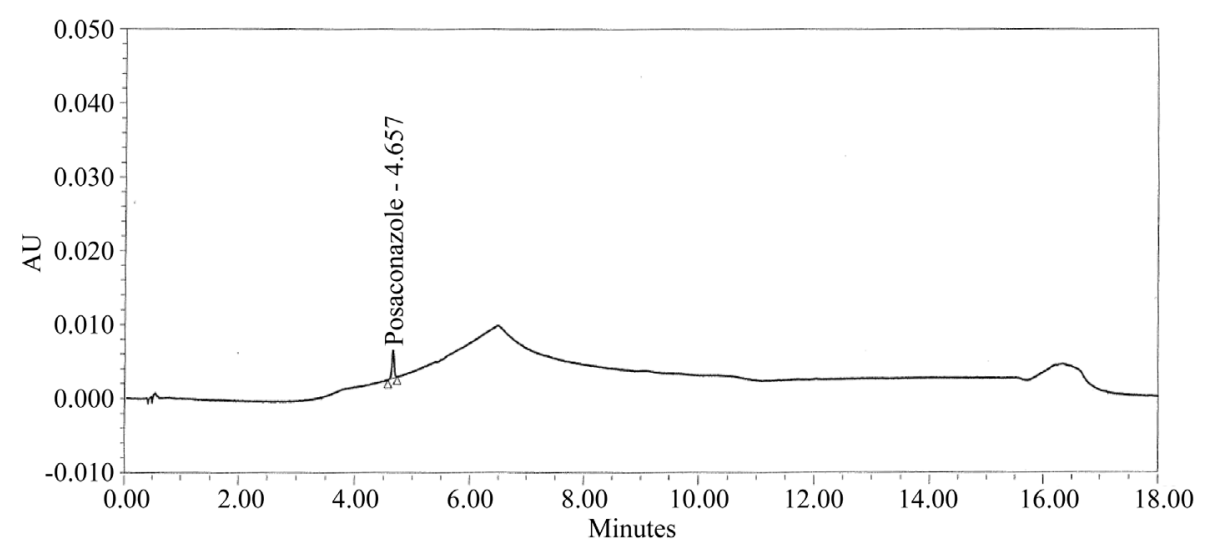

Figure 3. Chromatogram of POS standard solution. 


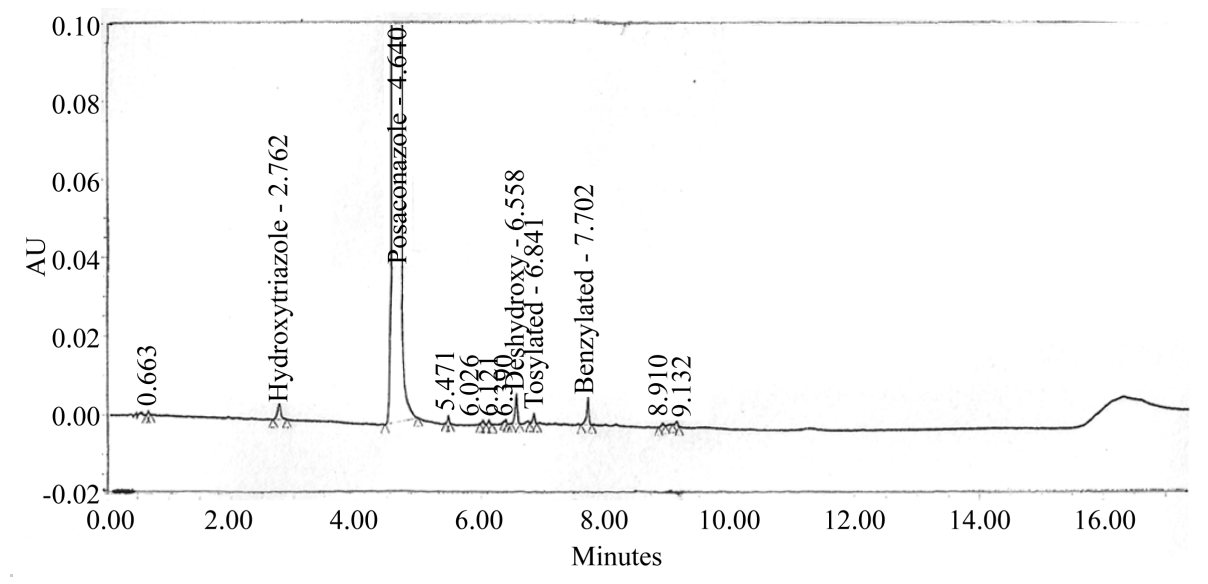

Figure 4. Chromatogram of POS system suitability solution.

Table 2. Specificity part-B (stress) studies representing degradation in various parameters.

\begin{tabular}{|c|c|c|c|c|c|c|c|c|}
\hline \multirow{2}{*}{$\begin{array}{c}\text { Degradation } \\
\text { stages }\end{array}$} & \multirow{2}{*}{ Condition } & \multicolumn{6}{|c|}{$\%$ Impurities calculated against $0.1 \%$ POS standard } & \multirow{2}{*}{$\begin{array}{c}\text { Mass } \\
\text { balance } \\
(\%)\end{array}$} \\
\hline & & Hydroxytriazole & Tosylated & Deshydroxy & Benzylated & SMUI (\%) & $\begin{array}{c}\text { \% Total } \\
\text { impurities }\end{array}$ & \\
\hline As such & Initial & ND & ND & 0.06 & 0.04 & 0.04 & 0.25 & 104.0 \\
\hline Acid & $60^{\circ} \mathrm{C}, 3 \mathrm{hrs}$ & ND & ND & 0.10 & 0.05 & 0.11 & 0.43 & 104.3 \\
\hline Base & $60^{\circ} \mathrm{C}, 3 \mathrm{hrs}$ & ND & ND & 0.07 & 0.04 & 0.04 & 0.25 & 103.5 \\
\hline Peroxide & $60^{\circ} \mathrm{C}, 3 \mathrm{hrs}$ & ND & ND & 0.02 & 0.01 & 48.70 & 70.14 & 100.8 \\
\hline Neutral & $60^{\circ} \mathrm{C}, 3 \mathrm{hrs}$ & ND & ND & 0.08 & 0.04 & 0.04 & 0.26 & 104.7 \\
\hline Thermal & $80^{\circ} \mathrm{C}, 24 \mathrm{hrs}$ & ND & ND & 0.08 & 0.04 & 0.05 & 0.32 & 104.0 \\
\hline Sun light & $3 \mathrm{hrs}$ & ND & ND & 0.04 & 0.06 & 1.31 & 4.09 & 102.5 \\
\hline
\end{tabular}

As such $=$ No stress condition applied, ND = Not detected, SMUI = Single maximum unknown impurity.

of POS is shown in Figure 5.

\subsubsection{Degradation in Basic Conditions}

POS was found stable in basic conditions, when hydrolyzed with $0.1 \mathrm{M} \mathrm{NaOH}$ for $3 \mathrm{~h}$ at $60^{\circ} \mathrm{C}$. Basic degradation of POS is shown in Figure 6.

\subsubsection{Degradation under Oxidative Conditions}

The POS drug was reduced to $70 \%$ on peroxide degradation $\left(1 \% \mathrm{H}_{2} \mathrm{O}_{2}\right.$ at $60^{\circ} \mathrm{C}$ for $\left.3 \mathrm{~h}\right)$ with as a major degradation product (48.70\%) eluting at $0.41 \mathrm{RRT}$ and other major degradant (10\%) at $0.55 \mathrm{RRT}$. The chromatogram obtained on hydrolysis of POS under oxidative conditions is shown in Figure 7.

\subsubsection{Degradation in Photolytic Conditions}

POS was found to be slightly sensitive under the exposed conditions with sunlight for about 3 hours (about 200 $\mathrm{MW} / \mathrm{km}$ ), the chromatogram is given in Figure 8. This suggests that the drug was sensitive under photolytic conditions exposed for the period of study.

\subsubsection{Thermal Degradation}

POS was found to be practically stable with dry heat as no degradation was observed when exposed to thermal heat at $80^{\circ} \mathrm{C}$ for 24 hours; the chromatogram is shown in Figure 9 . 


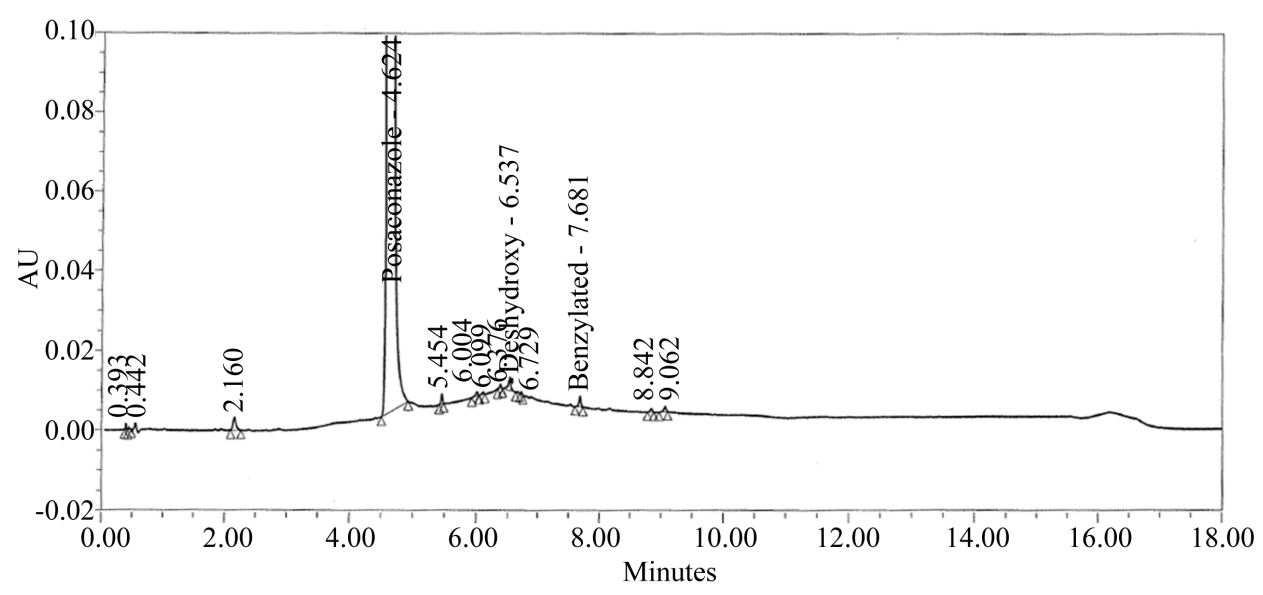

Figure 5. Chromatograms of acid stressed samples treated with $0.1 \mathrm{M} \mathrm{HCl}$ at $60^{\circ} \mathrm{C}$ for 3 hours.

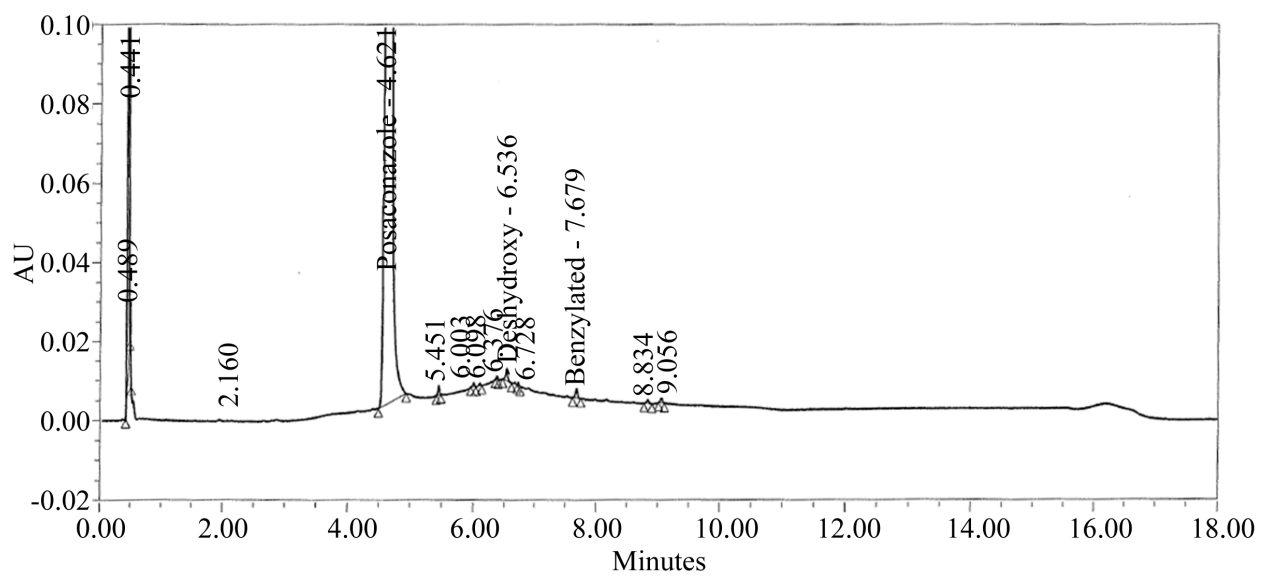

Figure 6. Chromatograms of base stressed samples treated with $0.1 \mathrm{M} \mathrm{NaOH}$ at $60^{\circ} \mathrm{C}$ for 3 hours.

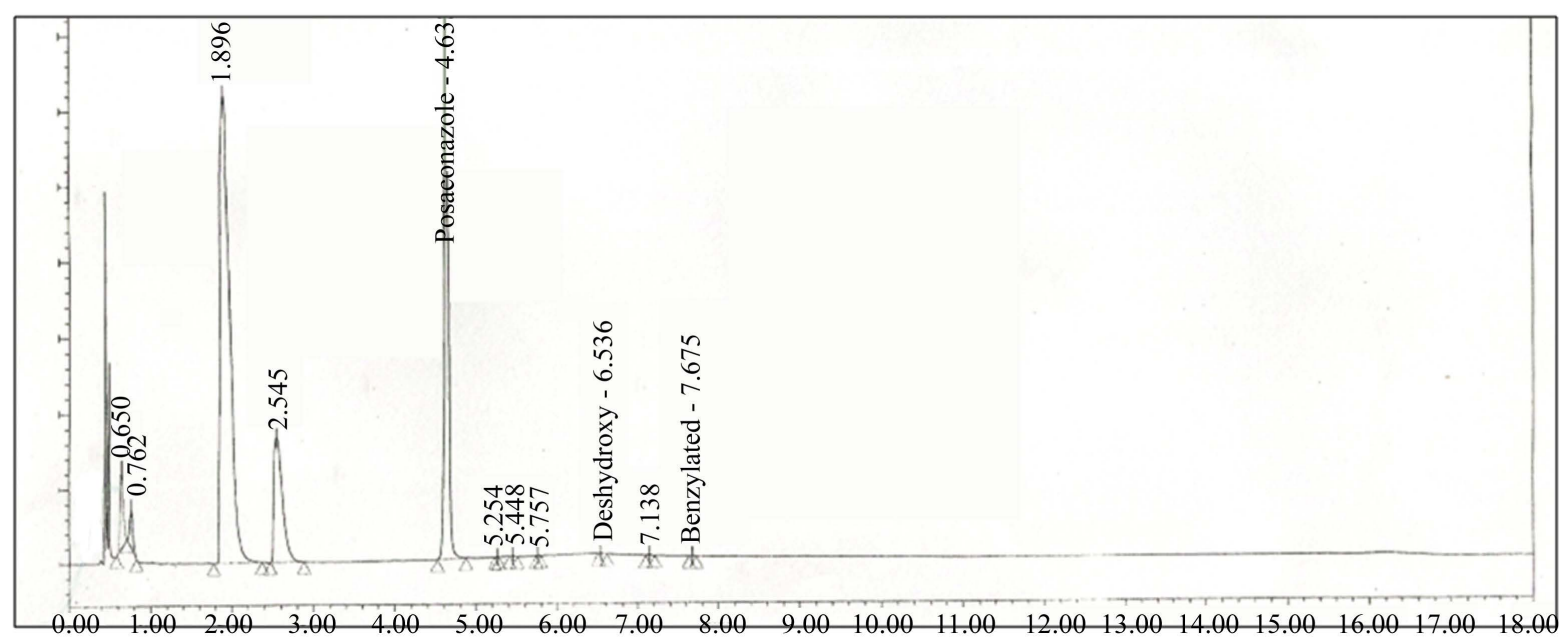

Figure 7. Chromatograms of oxidation stressed samples treated with $1 \%$ Peroxide at $60^{\circ} \mathrm{C}$ for 3 hours.

3.3.6. Degradation under Neutral Conditions

POS was found stable under neutral conditions (refluxed in water for $3 \mathrm{~h}$ at $60^{\circ} \mathrm{C}$ ) the chromatogram is given in Figure 10. 


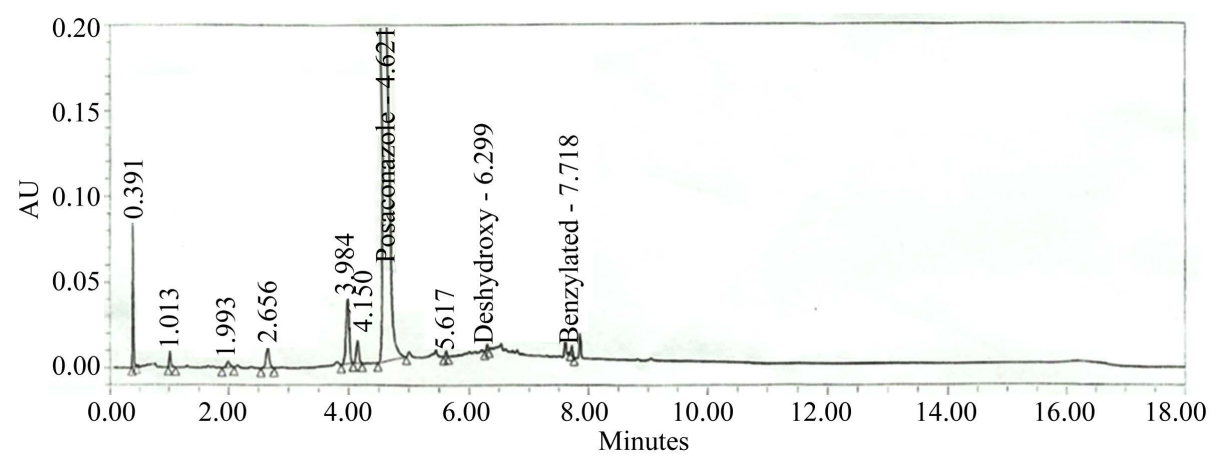

Figure 8. Chromatograms of samples exposed under sun light for 3 hours.

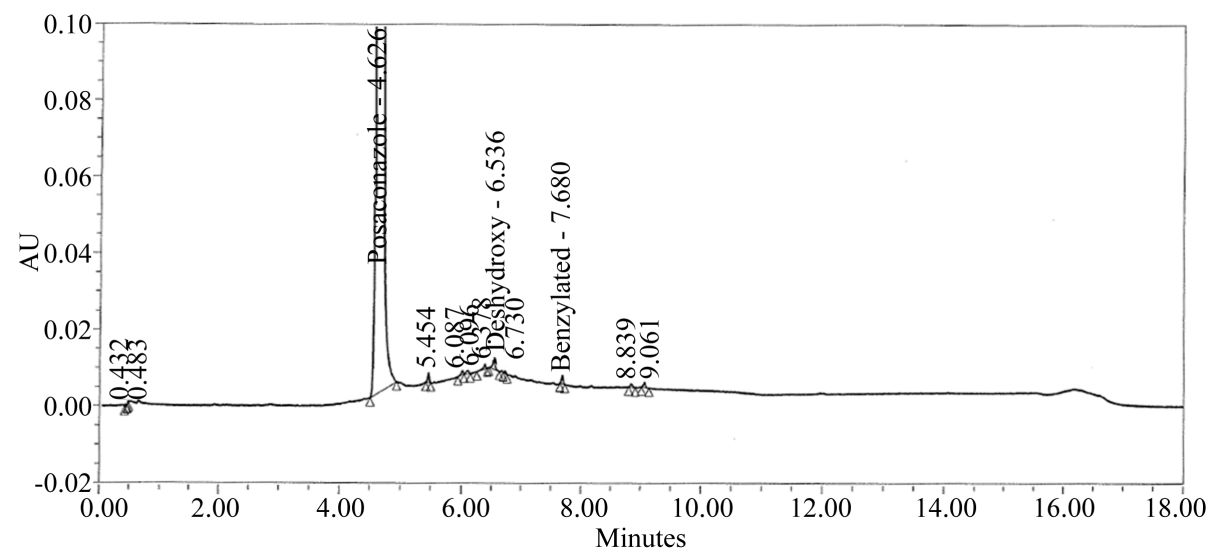

Figure 9. Chromatograms of samples exposed to dry heat at $80^{\circ} \mathrm{C}$ for 24 hours.

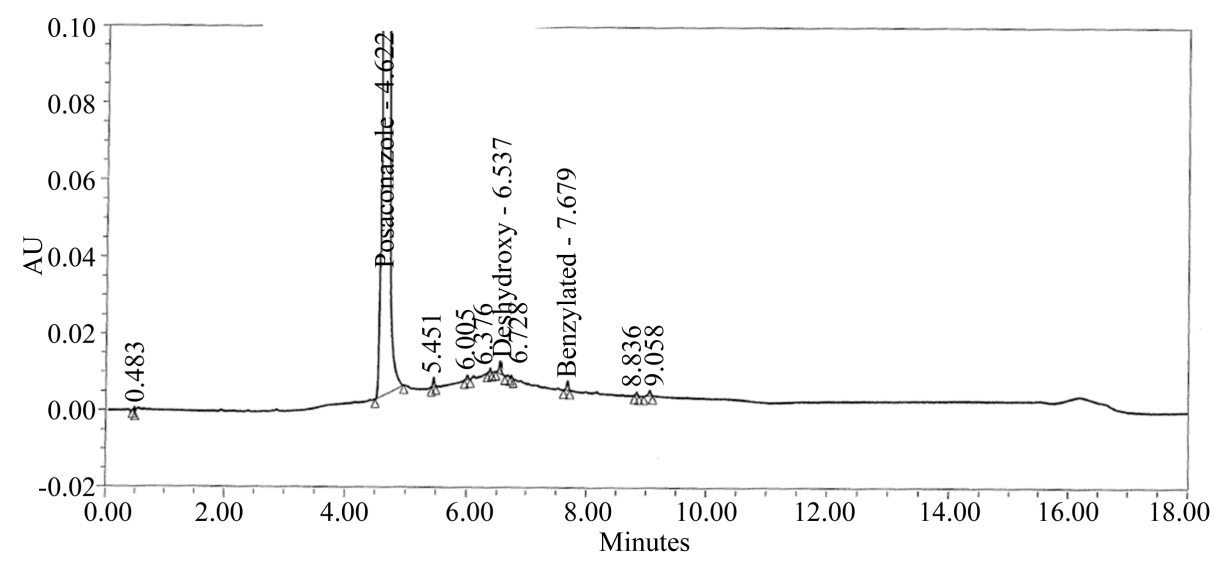

Figure 10. Chromatograms of samples treated with water at $60^{\circ} \mathrm{C}$ for 3 hours.

\subsection{Linearity}

Linearity curves for POS and its related compounds, examined with the impurity stock solutions, were found to be linear; correlation coefficients $\geq 0.999$ in all the cases. Table 1 gives the linearity parameters of the calibration curves for POS and its related compounds in laboratory mixture. The correction factor (CF) was calculated for each impurity using the following equation: $\mathrm{CF}=S_{\text {impurity }} / S_{P O S}$.

Where, $S_{\text {impurity }}$ is the slope of the regression line for a given impurity and $S_{P O S}$ is the slope of the regression line for POS. Concentrations of POS and impurities were corrected. Linearity data of POS and its related impurities shows a linear response from Quantification level to $180 \%$ of sample concentration. Likewise the analysis 
of residuals shows values randomly scattered around zero, which fits well within the linear model.

\subsection{LOD and LOQ}

Limit of detection and Limit of quantification are the measure of method sensitivity, were provided for known and unknown impurities calculated by means of signal-to-noise ratio. The LOD and LOQ for POS and its related impurities are tabulated in Table 3. Obtained values are below the reporting threshold value of impurities as per ICH guidelines.

\subsection{Precision and Repeatability}

The results obtained for repeatability studies and for intermediate precision are presented in Table 4. Values of \% RSD for system precision of known impurities of POS and total impurities were less than 10 . The results show that the Method for determination of related substances of POS is precise.

\subsection{Accuracy}

The accuracy of the method is established by spiking the impurities at different concentration levels to the samples. Table 5 shows that the overall percent recoveries of POS related impurities at LOQ, 100, and 180\% of the test concentration. The method has shown good, consistent recoveries for Hydroxytriazole (97\% - 103\%, \%RSD3.07), Tosylated compound (90\% - 103\%, \%RSD-7.14), Deshydroxy posaconazole (100\% - 106\%, \%RSD-2.96) and Benzylated posaconazole (89\% - 98\%, \%RSD-5.34).

\subsection{Stability in Analytical Solution}

The response ratio obtained for POS standard after bench top was found 0.95 with the initial, which shows standard solution is stable up to 48hrs at Bench top. The \% Impurity difference for all known impurities at different levels was less than 0.03. From the data tabulated in Table 6, it was concluded that standard and sample solutions can be used up to 48 after preparation.

Table 3. LOD and LOQ results for POS and its related impurities.

\begin{tabular}{|c|c|c|c|c|c|c|}
\hline \multirow{3}{*}{ Compound } & \multicolumn{3}{|c|}{ LOD } & \multicolumn{3}{|c|}{ LOQ } \\
\hline & \multicolumn{2}{|c|}{ Concentration } & \multirow{2}{*}{$\mathrm{s} / \mathrm{n}$} & \multicolumn{2}{|c|}{ Concentration } & \multirow{2}{*}{$\mathrm{s} / \mathrm{n}$} \\
\hline & $(\mathrm{mg} / \mathrm{mL})$ & \% w.r.t sample & & $(\mathrm{mg} / \mathrm{mL})$ & \% w.r.t sample & \\
\hline POS & 0.000311 & 0.015 & 2.71 & 0.001038 & 0.05 & 9.65 \\
\hline Hydroxytriazole & 0.000327 & 0.015 & 4.22 & 0.001090 & 0.05 & 13.39 \\
\hline Tosylated & 0.000318 & 0.015 & 2.85 & 0.001060 & 0.05 & 8.72 \\
\hline Deshydroxy & 0.000309 & 0.015 & 5.41 & 0.001030 & 0.05 & 19.98 \\
\hline Benzylated posaconazole & 0.000323 & 0.015 & 2.22 & 0.001076 & 0.05 & 8.96 \\
\hline
\end{tabular}

Table 4. Intra-day and intermediate precision of POS and its RS (\% RSD of $n=6$ injections of test concentration).

\begin{tabular}{ccc}
\hline Compound & Intra-day precision & Intermediate precision \\
Dethod precision & 1.58 & 1.23 \\
Total & 1.93 & 1.94 \\
Hydroxytriazole & 5.29 & 3.37 \\
Tosylated & 5.97 & 1.13 \\
Deshydroxy & 1.39 & 1.81 \\
Benzylated posaconazole & &
\end{tabular}


Table 5. Accuracy results of POS related compounds in the term of RSD (\%) of mean recovery (\%).

\begin{tabular}{ccccc}
\hline \multirow{2}{*}{ \% Recovery level } & \multicolumn{3}{c}{ \% Mean Recovery } \\
\cline { 2 - 5 } & Hydroxy triazole & Tosylated compound & Deshydroxy posaconazole & Benzylated posaconazole \\
\hline LOQ & 103 & 103 & 106 & 89 \\
$100 \%$ & 99 & 90 & 100 & 98 \\
$180 \%$ & 97 & 93 & 104 & 90 \\
Mean & $\mathbf{1 0 0}$ & $\mathbf{9 5}$ & $\mathbf{1 0 3}$ & $\mathbf{4 . 9 3 3}$ \\
Std. Dev & $\mathbf{3 . 0 5 5}$ & $\mathbf{6 . 8 0 7}$ & $\mathbf{3 . 0 5 5}$ & $\mathbf{5 . 3 4}$ \\
\hline
\end{tabular}

Table 6. Stability of in analytical solution used for POS related substances.

\begin{tabular}{|c|c|c|c|c|c|c|}
\hline $\begin{array}{l}\text { Solution } \\
\text { stability }\end{array}$ & $\begin{array}{c}\text { \% Accuracy } \\
\text { level }\end{array}$ & $\begin{array}{l}\text { Tosylated } \\
\text { compound }\end{array}$ & $\begin{array}{l}\text { Hydroxy } \\
\text { triazole }\end{array}$ & $\begin{array}{l}\text { Deshydroxy } \\
\text { posaconazole }\end{array}$ & $\begin{array}{c}\text { Benzylated } \\
\text { posaconazole }\end{array}$ & Total \\
\hline Initial & & 0.108 & 0.115 & 0.124 & 0.105 & 0.454 \\
\hline After 48 hours Bench top & 100\% Level & 0.100 & 0.135 & 0.122 & 0.115 & 0.472 \\
\hline Difference & & 0.01 & -0.02 & 0.00 & -0.01 & -0.02 \\
\hline Initial & & 0.204 & 0.217 & 0.225 & 0.201 & 0.847 \\
\hline After 48 hours Bench top & 180\% Level & 0.190 & 0.233 & 0.242 & 0.21 & 0.847 \\
\hline Difference & & 0.01 & -0.02 & -0.02 & -0.01 & 0.00 \\
\hline
\end{tabular}

\subsection{Robustness}

The robustness of the method is verified for the method by changing small variations of chromatographic conditions by changing the mobile phase flow rate $( \pm 0.05 \mathrm{~mL} / \mathrm{min})$, and increasing the temperature from normal $\left( \pm 5^{\circ} \mathrm{C}\right)$. Chromatograms of POS standards and system suitability solutions were evaluated by applying system suitability parameters with the robustness changes made. There are no variations observed in system suitability criteria and results obtained for as such sample and spiked sample.

\section{Conclusion}

The proposed simple UPLC method for estimation of related substances for POS is analyzed in bulk drug as per ICH guidelines. The method is found to be specific, precise, accurate and robust for the estimation of known, unknown impurities and degradation products. The method is also stability indicating as evident from mass balance results obtained when samples were stressed to degradation studies. The method is also shown green chromatography with less consumption of organic phase used for the analysis. Hence, the proposed method stands validated and may be used for routine and stability sample analysis of POS.

\section{References}

[1] (2014) Posanol (Posaconazole) Product Monograph, Merck Canada Inc.

[2] Noxafil: EPAR_European Medicines Agency-Europa Annex I Summary of Product Characteristics.

[3] Schering Corporation (2009) Noxafil (Posaconazole) Oral Suspension Prescribing Information. Kenilworth.

[4] Keating, G.M. (2005) Posaconazole. Drugs, 65, 1553-1569. http://dx.doi.org/10.2165/00003495-200565110-00007

[5] Torres, H.A., Hachem, R.Y., Chemaly, R.F., et al. (2005) Posaconazole: A Broad-Spectrum Triazole Antifungal. The Lancet Infectious Diseases, 5, 775-785. http://dx.doi.org/10.1016/S1473-3099(05)70297-8

[6] Dodds Ashley, E.S., Varkey, J.B., Krishna, G., et al. (2009) Pharmacokinetics of Posaconazole Administered Orally or by Nasogastric Tube in Healthy Volunteers. Antimicrobial Agents and Chemotherapy, 53, 2960-2964. 
http://dx.doi.org/10.1128/AAC.01178-08

[7] ICH (2003) Stability Testing of New Drug Substances and Products. Q1A (R2).

[8] ICH (2006) Impurities in New Drug Substances. Q3A (R1).

[9] ICH (2006) Impurities in New Drug Products. Q3B (R1).

[10] Reddy, S.K., Govind, N.Ch.V.S., Rajan, S.T., Eshwaraiah, S., Chakravarthy, I.E., Rakesh, M. and Kishore, M. (2014) Stability Indicating HPLC Method for the Quantification of Posaconazole and Its Related Substances. Der Pharma Chemica, 6, 486-494.

[11] Triazole Adverse Effects, Toxicity, and Safety Russell Lewis. University of Houston College of Pharmacy, University of Texas, Anderson Cancer Center, Houston.

[12] (2005) Validation of Analytical Procedures: Text and Methodology. Q2 (R1).

[13] Singh, S. and Bakshi, M. (2002) Development of Stability Indicating Assay Methods—A Critical Review. Journal of Pharmaceutical and Biomedical Analysis, 28, 1011-1040. http://dx.doi.org/10.1016/S0731-7085(02)00047-X

[14] Kathirvel, S., Raju, R., Seethadevi, B., Suneetha, A. and Pavani, J. (2014) Stability Indicating RP-HPLC Method for the Determination of Process Related Impurities in Posaconazole API. Asian Journal of Pharmacy and Technology, 4, 167-178. 